\title{
OPEN PNEUMOTHORAX IN ITS RELATION TO THE EXTIRPATION OF TUMORS OF THE BONY CHEST WALL *
}

\author{
CARL A. HEDBLOM, M.D. \\ ROCHESTER, MINN.
}

Perhaps no surgical condition of the chest is more germane to the discussion of pneumothorax than that of tumors of the bony chest wall. Such tumors are usually either malignant or potentially malignant, and often involve an extensive portion of the wall of the thorax. Complete extirpation with a wide margin necessitates an extensive resection, and furthermore, this operation, usually performed in one stage, results in a sudden collapse of the lung. In contrast to conditions following surgery for infectious diseases, there are no inflammatory adhesions of the pleura, and no thickening and fixation of the mediastinum. The posture of the patient, which is usually lateral or dorsal, is favorable to the collapse of the lung and to the transmission of atmospheric pressure to the other side. The operation is concerned with the chest wall, and not with the lung; retraction of a lobe of the lung outside the wound is neither necessary nor convenient during resection. There is consequently no steadying of the mediastinum. A study of operative pneumothorax incident to the resection of tumors under such conditions should be of importance, both with respect to the theoretical and to the practical considerations of the subject.

Resection of the entire chest wall with wide opening of the pleural cavity was practiced before the nature of pneumothorax or the dangers incident to it were adequately conceived. The first case of thoracotomy for tumor was recorded by Osias Aimar, ${ }^{1}$ who, in 1778, removed an osteosarcoma involving the fifth, sixth, and seventh ribs; but he did not open the pleura. The first case of thoracotomy for tumor in which pneumothorax resulted was reported, in 1818 , by Richerand, ${ }^{2}$ who, with the assistance of Dupuytren, widely opened the pleural cavity by resecting a portion of the pleura with a carcinomatous growth involving the ribs. Richerand describes the onset of the pneumothorax, as follows:

* From the Section on Surgery, Mayo Clinic.

* Read before the fourth annual meeting of the American Association for Thoracic Surgery, Boston, June, 1921.

1. Aimar, Osias: Quoted by Parham, F. W.: Thoracic Resection for Tumors Growing from the Bony Wall of the Chest, New Orleans, 1899.

2. Richerand, quoted by Parham: Footnote 1 , second reference. 
"At this moment the exterior air made an eruption into the chest, rushing in with violence and compressing the left lung which, with the heart, was borne toward the orifice. I sought, by placing thereto the left hand, to moderate the entrance of air and to prevent suffocation, which appeared imminent, while with the right hand I applied to the wound a large bolster spread with cerate. The entrance of air was suddenly stopped by this greasy cloth." The patient recovered from the operation, but died of recurrence one month later.

It was not until 1855 that Sedillot ${ }^{3}$ performed the second recorded intrapleural operation. In an exhaustive review of the literature from then until 1898, Parham ${ }^{4}$ was able to collect twenty-six cases in which resections were performed without opening the pleural cavity, and fifty-four, including two of his own, in which it was opened. Of twenty-three additional cases of resection of the sternum, pneumothorax resulted in six. In one instance, both pleural cavities were opened, with resulting bilateral pneumothorax. The patient recovered. In considering the effect of pneumothorax, Parham classified forty-one selected cases into three groups: (1) those in which little or no disturbance followed opening of the pleural cavity, sixteen cases; (2) those in which there was moderate disturbance, ten cases, and (3) those in which there was marked disturbance, ten cases. He concludes that the size of the opening and the duration of the open pneumothorax are the most important factors in producing symptoms. $\mathrm{He}$ found that the respiration was interfered with to some extent in all, and that seven of the patients suffered severe collapse. In cases of extensive resection involving adjacent structures, such as the diaphragm and pericardium, he accredited the serious symptoms to the prolongation of the operation rather than to the severity of the procedure.

In 1898, Parham used the differential pressure method of FellO'Dwyer in operating on a patient with chrondrosarcoma. $\mathrm{He}$ employed positive pressure to inflate the lung, which was then sutured to the parietal pleura, after which he dispensed with the apparatus. A thorough search of the literature has brought to light reports of sixty-seven cases of tumor of the chest wall in which operation was performed since Parham's first patient was operated on undar differential pressure. This includes twenty-eight cases reported by Lund, ${ }^{5}$ in 1913, and one case in which he operated under intratracheal insuffla-

3. Sedillot, quoted by Parham: Footnote 1, second reference.

4. Parham. F. W.: Thoracic Resection for Tumors Growing from the Bony Wall of the Chest, New Orleans, 1899.

5. Lund. F. B.: Sarcoma of the Chest Wall, Ann. Surg. 58:206-217, 191.3 
tion. The case reports of Gross, ${ }^{6}$ Stukkei, ${ }^{7}$ Hervy, ${ }^{8}$ Degorce, ${ }^{9}$ Palleroni, ${ }^{10}$ and Zschucke ${ }^{11}$ unfortunately were not available for this study.

The records of the Mayo Clinic since 1910 contain the histories of forty-nine patients with tumors of the bony chest wall. A complete report of these cases has been published recently. ${ }^{12}$ Fifteen have been included in this study as having a bearing on the theme. With the fiftyeight cases from the literature, the total is eighty-two cases.

OPERATIONS UNDER DIFFERENTIAL PRESSURE

Eighteen (about 20 per cent.) of the eighty-two patients were operated on under differential pressure anesthesia. The type of differential pressure apparatus used was the Fell-O'Dwyer apparatus in one operation; Brauer's positive pressure chamber in four operations; Sauerbruch's negative pressure chamber in six, and Murphy's chamber in one operation. Intratracheal insufflation was used in four operations and intrapharyngeal insufflation in two.

Chloroform anesthesia was used in five operations, ether in eight, nitrous oxid and oxygen in one, and the anesthetic was not mentioned in four.

The resection was performed for chondroma in three, for sarcoma in nine, for endothelioma in one, for recurrent carcinoma following amputation of the breast in four, and for chronic inflammation in one.

The opening in the chest wall was stated or was suggested by the context to be small in one case ( $4 \mathrm{~cm}$. in diameter); moderately large ("Handteller Grösse") in eight, and large $(10 \mathrm{~cm}$. by $18 \mathrm{~cm}$.) in six. In one case, the size of the opening could not be determined, and in two, an opening was not made in the pleura.

The symptoms referable to the opening of the pleural cavity were weak, rapid pulse, and disturbed respiration in the two cases of Por-

6. Gross, G.: Sarcomes étendus de la région sterno-claviculaire; exstirpation; autoplastie par glissement et décollement, Rev. méd. đe l'est. 45:497-500, 1913.

7. Stukkei, L. G.: Case of Chondrosarcoma of the Manubrium Sterni, Russk. Vrach. 14:977, 1915.

8. Hervy, J. M. J.: La chondrectomie (operation de Freund) est-elle une intervention bénigne? Bordeaux, Cadoret, 1915.

9. Degorce, A.: Sarcome de la paroi antéro-latérale du thorax à prolongement intrathoracique, Bull. Soc. méd.-chir. de l'Indo-Chine 5:160, 1914.

10. Palleroni, G.: Sopra un caso di encondrosarcoma della parete toracica, Clin. mod. 9:393-396, 1903.

11. Zschucke, J.: Ueber einen Fall von Myxochondrosarkom der Rippe bei einem zwölfjährigen Mädchen, München, Müller and Steinicke, 1912.

12. Hedblom, C. A.: Tumors of the Bony Chest Wall, Arch. Surg. 3:56-85 (July) 1921. 
ter ${ }^{13}$ and Payr. ${ }^{14}$ In both of these cases the diaphragm was resected, and the symptoms promptly abated. Pleural effusion occurred in one patient as a postoperative complication. Porter's patient died on the fourteenth day, and purulent bronchitis and pneumonia were found at necropsy.

\section{OPERATIONS WITHOUT DIFFERENTIAL PRESSURE}

Sixty-four patients were operated on without differential pressure. The ribs and adjacent structures included in the resection are listed in Table 1 .

Chloroform was used for fifteen patients, gas and ether for one patient, and ether for fourteen patients; the anesthetic for the others was not mentioned. Pneumothorax was produced in forty-three of the patients, in two bilaterally. In the remaining twenty-one patients, the pleura was not opened, or there were extensive adhesions.

TABLE 1.-Extent of Resection

\begin{tabular}{|c|c|c|c|c|c|c|c|c|c|}
\hline \multirow[t]{2}{*}{$-\cdots-\cdots$} & \multirow[b]{2}{*}{ Crises } & \multicolumn{8}{|c|}{ Structures Resected with Ribs } \\
\hline & & $\begin{array}{c}\text { Clavi- } \\
\text { cle and } \\
\text { Sternum }\end{array}$ & $\underset{\text { phragm }}{\text { Dia- }}$ & $\begin{array}{l}\text { Carti- } \\
\text { lages }\end{array}$ & $\begin{array}{l}\text { Dla- } \\
\text { phragm } \\
\text { and } \\
\text { Peri- } \\
\text { toneum }\end{array}$ & $\left|\begin{array}{c}\text { Dia- } \\
\text { phragm } \\
\text { Pericar- } \\
\text { cilum and } \\
\text { Lung }\end{array}\right|$ & Sternum & Lung & $\begin{array}{c}\text { Peri- } \\
\text { cardium }\end{array}$ \\
\hline $\begin{array}{l}\text { One rib....... } \\
\text { Two ribs..... } \\
\text { Three ribs... } \\
\text { Four ribs..... } \\
\text { Five ribs...... } \\
\text { Sternum...... } \\
\text { Vertebra...... } \\
\text { Structure not } \\
\text { mentioned.. }\end{array}$ & $\begin{array}{r}11 \\
26 \\
18 \\
15 \\
1 \\
11 \\
1 \\
7\end{array}$ & $\begin{array}{l}2 \\
4 \\
\cdots \\
\cdots \\
\cdots \\
\cdots \\
\ldots\end{array}$ & $\begin{array}{l}1 \\
2 \\
3 \\
3 \\
\cdots \\
\cdots \\
\cdots \\
\end{array}$ & $\begin{array}{l}\cdots \\
\cdots \\
\cdots \\
\ddot{2} \\
\cdots \\
\cdots\end{array}$ & $\begin{array}{l}\ddot{1} \\
1 \\
\cdots \\
\cdots \\
\cdots \\
\cdots\end{array}$ & $\begin{array}{l}\cdots \\
\ddot{*} \\
\ddot{1} \\
\cdots \\
\cdots \\
\ldots\end{array}$ & $\begin{array}{l}\cdots \\
\ddot{1} \\
\cdots \\
\cdots \\
\cdots\end{array}$ & $\begin{array}{l}\cdots \\
\ddot{1} \\
\ddot{1} \\
\cdots \\
\cdots\end{array}$ & $\begin{array}{l}1 \\
\ldots \\
\cdots \\
\cdots \\
\cdots \\
\cdots\end{array}$ \\
\hline Total..... & 84 & 11 & 9 & 2 & 2 & 1 & 1 & 1 & 1 \\
\hline
\end{tabular}

In the forty-three cases in which the pleural cavity was opened without differential pressure with resulting pneumothorax, the opening was stated or suggested to be small in nine, moderately large in three (about $7 \mathrm{~cm}$. in diameter), and large in twenty-three. In the other cases the size of the opening was not mentioned. In several, the opening was so large that "both hands could be introduced at once into the pleural cavity."

It may be noted in Table 2 that of the forty-three patients in whom pneumothorax was produced there were symptoms referable to it in nine, and there were no symptoms in twenty-six. Symptoms were not mentioned in eight. Postoperative symptoms were designated as shock

13. Porter, C. A.: Two Cases of Extensive Thoracic Resections: The First for Enchondroma of the Ribs, the Second for a Closed Tuberculous Empyema of Many Years' Duration, Boston M. \& S. J. 159:861-864, 1908. 1911.

14. Payr: Fibrosarkom der Brustwand, Deutsch. med. Wchnschr. 37:1147, 
in nine ; there were no symptoms in eighteen, and no mention of symptoms was made in sixteen. Of the patients without pneumothorax, there was postoperative shock in three, no symptoms in ten, and no mention of symptoms in eight. Table 2 shows, therefore, that while the majority of the patients with pneumothorax do not have marked symptoms referable to it, and only a very small percentage have symptoms at the time of operation, the incidence of postoperative shock is considerably greater if pneumothorax is produced. That this is largely due to the relatively greater extent of the operation on the latter is

TABle 2.-Symptoms at the Time of Operation and After Operation

\begin{tabular}{|c|c|c|c|}
\hline \multirow{7}{*}{ 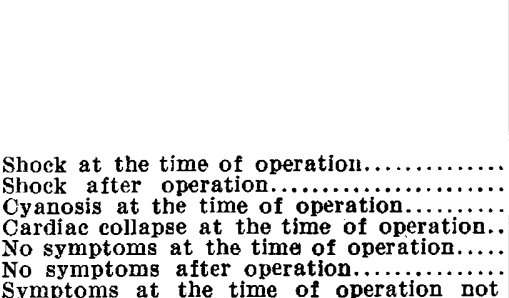 } & \multirow{3}{*}{$\begin{array}{c}\text { Patients } \\
\text { Operated on } \\
\text { With Differen- } \\
\text { tiai Pressure } \\
\text { Anesthesia } \\
\text { Without Pneu- } \\
\text { mothorax } \\
3 \\
1\end{array}$} & \multicolumn{2}{|c|}{$\begin{array}{c}\text { Patients Operated on } \\
\text { Without } \\
\text { Differential Pressure } \\
\text { Anesthesia }\end{array}$} \\
\hline & & $\begin{array}{l}\text { With Pneu- } \\
\text { mothorax } \\
5\end{array}$ & $\begin{array}{l}\text { Without Pneu- } \\
\text { mothorax }\end{array}$ \\
\hline & & $\stackrel{5}{9}$ & $\ddot{3}$ \\
\hline & . & 3 & $\therefore$ \\
\hline & $\because$ & 1 & $\ddot{i}$ \\
\hline & 6 & 26 & 10 \\
\hline & 7 & & \\
\hline 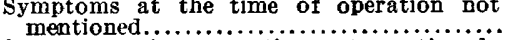 & & 8 & 11 \\
\hline Symptoms after operation not mentioned.. & 10 & 16 & 8 \\
\hline 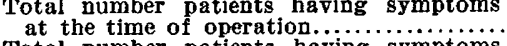 & 18 & 43 & 21 \\
\hline  & 18 & 43 & 21 \\
\hline
\end{tabular}

TABle 3.-Relation of Symptoms to Size of Pleural Opening

\begin{tabular}{|c|c|c|c|c|c|}
\hline Size of Opening & $\begin{array}{c}\text { No Symp- } \\
\text { toms }\end{array}$ & $\begin{array}{l}\text { Slight } \\
\text { Symptoms }\end{array}$ & $\begin{array}{l}\text { Marked } \\
\text { Symptoms }\end{array}$ & $\begin{array}{l}\text { Symptoms not } \\
\text { Mentioned }\end{array}$ & Total \\
\hline 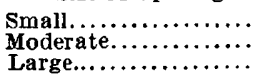 & $\begin{array}{r}4 \\
1 \\
14\end{array}$ & $\begin{array}{l}1 \\
2 \\
2\end{array}$ & $\ddot{4}$ & $\begin{array}{r}4 \\
\hdashline\end{array}$ & $\begin{array}{r}9 \\
3 \\
23\end{array}$ \\
\hline 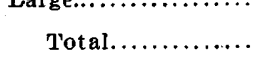 & $\frac{14}{19}$ & $\frac{2}{5}$ & $\frac{z}{4}$ & $\frac{3}{7}$ & $\frac{20}{35}$ \\
\hline
\end{tabular}

apparent from the fact that of the nine patients with marked shock after operation six had resections of adjacent structures, namely, the pericardium, the diaphragm, and in one case, the lung.

Table 3 shows that in five cases in which the opening into the pleural cavity was small, no symptoms were present in 80 per cent.; in twenty in which the opening was large, no symptoms occurred in 70 per cent., and marked symptoms were present in only 20 per cent. In the seven cases in which the opening was very large, there were no symptoms in two, slight symptoms in two, and marked symptoms in three. In the three with marked symptoms, the diaphragm was also resected in two. After suture the symptoms subsided.

Sufficient data were not forthcoming on which to base any observation as to the relation between the length of time the pleural cavity 
was opened and the relative incidence of symptoms. The depth of anesthesia, the relative conditions of the patients, and the position on the operating table are additional factors which produce uncertainty in attempts to estimate the direct relationship of the pneumothorax and the symptoms. In the absence of symptoms, however, it may be assumed that the pneumothorax was relatively harmless.

In several cases in the Mayo Clinic series, it was well shown that the extent of the operation plays a large part in the production of shock entirely independent of pneumothorax. Several of the patients were practically pulseless after leaving the operating room following

TABlE 4.-Postoperative Complications in Relation to Pneumothorax

\begin{tabular}{|c|c|c|c|}
\hline \multirow{3}{*}{ Bronchitis................... } & \multirow{2}{*}{$\begin{array}{c}\text { Patients Operated } \\
\text { on with Dif- } \\
\text { ferential } \\
\text { Pressure } \\
\text { Anesthesia }\end{array}$} & \multicolumn{2}{|c|}{$\begin{array}{c}\text { Patients Operated on Without Differ- } \\
\text { ential Pressure Anesthesia }\end{array}$} \\
\hline & & $\begin{array}{l}\text { With Pneumo- } \\
\text { thorax }\end{array}$ & $\begin{array}{l}\text { Without Pneumo- } \\
\text { thorax }\end{array}$ \\
\hline & $\ddot{i}$ & $\ddot{2}$ & 1 \\
\hline 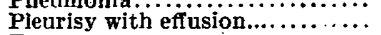 & 1 & 4 & $\because$. \\
\hline  & .. & & .. \\
\hline Pulmonary congestion. ............. & .. & 1 & $\because$ \\
\hline Anuria............................. & $\ddot{-}$ & $\ddot{-}$ & 1 \\
\hline Total.. ................. & 2 & 12 & 2 \\
\hline
\end{tabular}

TABLE 5.-Postoperative Mortality

\begin{tabular}{|c|c|c|c|}
\hline \multirow{2}{*}{ Oause of Death } & \multirow{2}{*}{$\begin{array}{c}\text { Patients Operated } \\
\text { on with Dif- } \\
\text { ferential } \\
\text { Pressure } \\
\text { Anesthesia }\end{array}$} & \multicolumn{2}{|c|}{$\begin{array}{c}\text { Patients Operated on Without Differ- } \\
\text { ential Pressure Anesthesia }\end{array}$} \\
\hline & & $\begin{array}{l}\text { With Pneumo- } \\
\text { thorax }\end{array}$ & $\begin{array}{l}\text { Without Pneumo- } \\
\text { thorax }\end{array}$ \\
\hline Pneumonia.................. & 1 & 1 & . \\
\hline 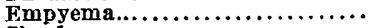 & . & $3^{*}$ & . \\
\hline Shock.......................... & $\cdots$ & 2 & $\because$ \\
\hline 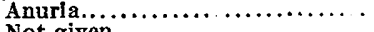 & . & $\because *$ & 1 \\
\hline Not given $\ldots \ldots \ldots \ldots \ldots \ldots \ldots \ldots$ & $\ddot{-}$ & $1^{*}$ & $\because$ \\
\hline Total.................... & 1 & 7 & 1 \\
\hline
\end{tabular}

* Double pneumothorax in one case.

resection for large tumors without opening of the pleural cavity. Loss of blood was slight, and in no case was the operation very long. Some of these patients were in fairly good condition; others were poor surgical risks. A two-stage or three-stage operation was performed in the latter cases. That a resection of the structures of the thoracic wall in itself produces shock is demonstrated in certain cases of radical amputation of the breast. Considerable shock may result in a patient who was a relatively good operative risk.

From Table 4, it will be observed that 11 per cent. of patients operated on with differential pressure anesthesia developed complications, while 28 per cent. of patients operated on without differential pressure anesthesia and in whom pneumothorax occurred developed 
complications. Pleural effusion, both serous and purulent, is of much greater incidence in cases in which pneumothorax is produced.

Table 5 shows that one death occurred on the fourteenth day in a patient operated on under differential pressure anesthesia. This case was reported by Porter who considered the differential pressure anesthesia largely contributory to the unfavorable outcome. One of the patients in the Mayo Clinic died of pulmonary edema the second day following operation for intrathoracic tumor under intratracheal anesthesia. Seven deaths followed operation in the cases in which differential pressure was not used, and in which pneumothorax occurred. In two of these, however, a bilateral pneumothorax had been produced. The mortality rate was about 5.5 per cent. for the first group and 16.3 per cent. for the second: If the cases of shock, which may have been due to other causes, are subtracted, the mortality rate drops to about 11 per cent. Pneumothorax did not occur in the patient with anuria.

\section{COMMENT}

The cases presented and the results obtained have significance in relation to the question of the actual immediate risk of open operative pneumothorax, and in relation to postoperative complications. It is obviously not only possible but reasonably safe, so far as the immediate risk to the life of the patient is concerned, to open wide the pleural cavity without differential pressure anesthesia. The experience of many operators has shown that in the majority of patients in whom a large opening of the pleura has been produced, with collapse of the lung, symptoms have been absent or slight. Furthermore, it is always possible to convert a large opening into a small opening, or completely to close the opening by drawing together the skin edges or by covering the opening with a wet towel. Experience has also seemed to show that traction on the lung will promptly relieve alarming symptoms referable to inefficient respiration. Whether the apparently slight effect produced by wide-open pneumothorax in so large a proportion of cases is due to a previous thickening of the mediastinum or to partial adhesions of the lung may be questioned. It is certain that there was massive collapse of the lung in many cases; but even granting the presence of a thickened mediastinum and possibly adhesions, and if it is further admitted that patients without thickened mediastinums and without adhesions would become asphyxiated by a large opening, the objection to operating without differential pressure anesthesia in such cases would be largely overcome by the fact that when alarming symptoms are presented it is a simple matter to convert the open pneumothorax into a closed pneumothorax. 
From a technical standpoint, however, an operation under differential pressure anesthesia can unquestionably be performed with greater assurance, less disturbance to the patient, and greater comfort to the surgeon. The impracticability to the average operator of differential pressure anesthesia chambers and the technical difficulties incident to the use of intratracheal insufflation and of other apparatus must be taken into consideration.

A study of these cases in relation to postoperative complications, with their increased mortality, indicates that the increased occurrence of complications furnishes the greatest support for the use of differential pressure anesthesia in resections for tumors of the chest wall. It has been demonstrated clinically and experimentally by Noetzel, ${ }^{15}$ Tiegel, ${ }^{16}$ Burkhardt, ${ }^{17}$ and others, that pneumothorax renders a pleural cavity less resistant to infection. Robinson and Sauerbruch ${ }^{18}$ showed that a sterile pleural effusion may develop, apparently due to the lack of contact between the pleurae. The presence of a dead space would also seem to contribute to a postoperative infection. The tendency to localization, as in the peritoneal cavity and, to some extent, in the normal pleural cavity, is absent. The aspiration of the air into the pleural cavity at operation probably also increases the risk of pulmonary infection. This could be largely obviated, however, by the use of gauze protection, as in abdominal surgery.

Empyema was the most potent cause of death in this group of cases; and it is reasonable to believe that the presence of pneumothorax at least contributed to the development of this complication. Therefore, from the standpoint both of maximum safety to the patient and of technical facility, differential pressure anesthesia is preferable in any case in which the thorax is likely to be opened wide and to remain open for some time. The greatest argument in favor of differential pressure anesthesia seems to rest in the fact that the development of postoperative complications, particularly pleural effusion, is apparently lessened by its use. This advantage may be gained, however, possibly equally well by some method of insuring an inflation of the lung at the end of the operation. In view of the advantages of local anesthesia for a preliminary incision, rib resection,

15. Noetzel, W., quoted by Sauerbruch, F.: Die Chirurgie der Brustorgane, Berlin, Springer 1:396, 1920.

16. Tiegel, M.: Ueber operative Pleurainfection und Thoraxdrainage, Arch. f. klin. Chir. 98:1022-1058, 1912; Experimentelle und klinische Studien über die postoperativen Komplikationen bei Eingriffen in der Brusthöhle, Beitr. z. klin. Chir. 80:128-156, 1912.

17. Burkhardt, quoted by Sauerbruch: Footnote 15, second reference.

18. Robinson, S., and Sauerbruch, F.: Untersuchungen über die Lungenexstirpation unter vergleichender Anwendung beider Formen des Druckdifferenzverfahrens, Deutsch. Ztschr. f. Chir. 102:542-560, 1909. 
and so forth, a combination of local anesthesia with some type of differential pressure anesthesia apparatus would make possible the inflation of the lung at the end of the operation before closure. This method was used in one case in the series in the Mayo Clinic and represents a maximum of simplicity and of operative and postoperative safety to the patient. A simple intrapharyngeal insufflation anesthesia by the use of a gas and oxygen apparatus achieves this result.

The foregoing deductions seem justified by the actual experience of many surgeons with different methods and by my experience with ten patients, some of whom were operated on with differential pressure anesthesia, and others without it. Although I have not entered into a discussion of the pathologic physiology of pneumothorax, I wish to point out that the explanation of the phenomena incident to pneumothorax is not simple.

The work of Graham and Bell, ${ }^{19}$ showing that in the normal thorax the pleural cavities function as one and that a change in pressure in one cavity is immediately transmitted to the other, seems fundamental to the study of the problem. This principle accounts for the prompt relief that results on converting an open pneumothorax into a closed pneumothorax, and for the relief obtained by traction on the exposed lung. It remains to be shown, however, why such a large proportion of patients do not develop alarming symptoms when the thorax is opened wide.

The symptoms produced in open pneumothorax are referable in the last analysis to disturbed circulation, to deficient aeration of the blood, and, possibly in some cases, to a pleural reflex. The return of the blood to the right side of the heart is dependent on the force of the heart's action through the capillaries, on the valve action in the veins, on the muscle tone as pointed out by Mann, ${ }^{20}$ and on the aspirating effect of the respiratory pump. In open pneumothorax, this aspiratory action is lost, and cyanosis and engorgement of peripheral veins develop. Deep anesthesia, resulting in loss of peripheral tone, further hampers venous return. Deficient venous return results in a lowered output from the heart, increased pulse rate, and, eventually, in a fall of blood pressure and shock. A positive pressure anesthesia apparatus provides for aeration of the blood, but does not furnish a substitute for the aspiratory action of normal respiration. Saurbruch holds that, on the contrary, positive pressure impedes the circulation in the lungs.

19. Graham, E. A., and Bell, R. D.: Open Pneumothorax: Its Relation to the Treatment of Empyema, Am. J. M. Sc. 156:839-871 (Dec.) 1918.

20. Mann, F. C.: Personal communication. 
Considerations which bear on the aeration of the blood are the relative amounts of blood passing through a collapsed lung as compared with that passing through a normal lung, the relative importance of the paradoxic respiration in the collapsed lung, the part played by the diaphragm, and the possible influence of disturbed nerve function. Other problems relate to the increased susceptibility of the pleural cavity in pneumothorax, to effusion and infection, and to the possible part of a pleural reflex in the sudden onset of symptoms incident to the abrupt collapse of the lung. 